\title{
Umidade de colheita, métodos de secagem e tempo de armazenamento na qualidade tecnológica de grãos de trigo (cv. 'Embrapa 16')
}

\author{
Harvest moisture, drying methods and storage period on the technological quality of wheat grains \\ (cv. 'Embrapa 16')
}

\author{
Moacir Cardoso Elias' ${ }^{\mathrm{I}}$ Vanessa Lopes II Luiz Carlos Gutkoski ${ }^{\text {III }}$ Maurício Oliveira ${ }^{\text {II }}$ \\ Simone Mazzutti ${ }^{\text {IV }}$ Alvaro Renato Guerra Dias ${ }^{\mathrm{I}}$
}

\section{RESUMO}

O objetivo deste trabalho foi estudar os sistemas umidades de colheita e métodos de secagem em função do período de armazenamento sobre a conservabilidade $e$ qualidade tecnológica de trigo. Grãos de trigo (Triticum aestivum L), cultivar 'Embrapa 16', produzidos na Granja Bretanhas, município de Jaguarão, Rio Grande do Sul (RS), safra agrícola de 1997/1998, foram colhidos secos naturalmente nas próprias plantas (14\% de umidade), com 16 e $18 \%$ de umidade. As amostras colhidas com umidade de 16 e $18 \%$ foram submetidas à secagem artificial pelo método intermitente, com ar a $70^{\circ} \mathrm{C}$; estacionário, com ar a $45^{\circ} \mathrm{C}$; e estacionário, com ar sem aquecimento. Os grãos secos foram armazenados em sistema convencional, pelo período de 12 meses, com a realização de avaliações a cada quadrimestre. $O$ trigo colhido seco na planta apresentou qualidade tecnológica inferior e menor conservabilidade ao armazenamento em comparação com o trigo colhido com umidade superior a $14 \%$ e seco em secador artificial.

Palavras-chave: Triticum aestivum, pós-colheita, conservabilidade, alveografia.

\section{ABSTRACT}

The objective of this research was to study the harvest moisture and drying method systems as a function to storage period on the conservability and technological quality of wheat. Grains of wheat (Triticum aestivum L), cultivar 'Embrapa 16', produced in the Granja Bretanhas, in Jaguarão, RS, agricultural harvest of 1997/1998 were harvested dry in the plant (14\% of moisture), with 16 and $18 \%$ of moisture. The samples harvested with moisture of 16 and $18 \%$ were submitted to artificial drying by intermittent method, with air at $70^{\circ} \mathrm{C}$, stationary, with air at $45^{\circ} \mathrm{C}$; and stationary, at room temperature. The grains were stored in a conventional system, during 12 months, with the realization of evaluations at 4 month intervals. Wheat grains harvested dry shown inferior technological quality and conservability in storage as compared to harvested with moisture above $14 \%$ and dry at artificial dryer.

Key words: Triticum aestivum, post-harvest, conservability, alveography.

\section{INTRODUÇÃO}

A qualidade do grão de trigo pode ser definida como resultado da interação que a cultura sofre no campo, do efeito das condições do solo, do manejo da cultura, da cultivar, bem como das operações de colheita, armazenamento e moagem (EDWARDS, 2004). Em condições inadequadas de colheita, secagem e armazenamento, o trigo pode sofrer alterações em suas propriedades físicas, químicas e reológicas, reduzindo o valor comercial e a funcionalidade da farinha (FLEURAT-LESSARD, 2002).

O teor de água dos grãos de trigo define o momento propício para a colheita, a temperatura e o tempo adequados para a secagem e o seu acondicionamento para o armazenamento ou processamento industrial na moagem (POSNER \&

'Departamento de Ciência e Tecnologia Agroindustrial, Faculdade de Agronomia Eliseu Maciel (FAEM), Universidade Federal de Pelotas (UFPel), Pelotas, RS, Brasil.

"Programa de Pós-graduação em Ciência e Tecnologia Agroindustrial, FAEM, UFPel, Pelotas, RS, Brasil.

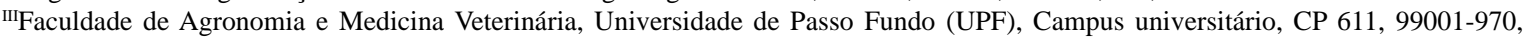

Passo Fundo, RS, Brasil. E-mail: gutkoski@upf.br. Autor para correspondência.

${ }^{\mathrm{IV}}$ Curso de Engenharia de Alimentos, UPF, Passo Fundo, RS, Brasil 
HIBBS, 1999). A colheita retardada, com permanência do grão na lavoura após a maturação fisiológica, ou a realização de secagem com temperaturas inadequadas em função do teor de umidade contribuem para alterações indesejáveis na qualidade tecnológica do trigo (CARNEIRO et al., 2005).

Dentre as etapas de pós-colheita do trigo, a secagem, quando não realizada adequadamente, pode provocar alterações na qualidade tecnológica do grão. A secagem pode ser realizada por meio de vários métodos, desde o natural até a secagem artificial, que inclui a estacionária e as convencionais contínua, intermitente e seca-aeração (BIAGI et al., 2002). Na secagem, devem ser evitadas fermentações durante o processo, assim como o excesso de temperatura. A secagem deve ser feita até a obtenção de um grau de umidade conveniente e de um produto uniforme (ELIAS et al., 2007).

No armazenamento com temperatura ou teor de água elevadas, pode ocorrer o desenvolvimento de pragas e fungos, que danificam os grãos e alteram a qualidade tecnológica da farinha (KOCH et al., 2006). A redução nos conteúdos de lipídios, carboidratos, proteínas e vitaminas, durante o período de armazenamento resulta em perdas de material orgânico, do peso hectolitro, da matéria seca, bem como do valor comercial e nutricional do trigo (FLEURAT-LESSARD, 2002). Os lipídios são os constituintes mais suscetíveis à degradação química e influenciam diretamente a secagem e conservabilidade do produto armazenado (RUPOLLO et al., 2004). A velocidade das alterações dos lipídios depende da umidade, da temperatura e do tempo de armazenamento (MARINI et al., 2005).

Além do esforço para o aumento da produção de grãos, é preciso incrementar as condições de acompanhamento das etapas de póscolheita. O objetivo deste trabalho foi estudar os sistemas umidades de colheita e métodos de secagem em função do período de armazenamento sobre a conservabilidade e qualidade tecnológica de trigo da cultivar 'Embrapa 16'.

\section{MATERIAL E MÉTODOS}

Foram utilizados grãos de trigo (Triticum aestivum L), cultivar 'Embrapa 16', produzidos em solo de várzea, tipo planossolo, na Granja Bretanhas, da Cooperativa Arrozeira Extremo Sul, localizada no município de Jaguarão, Rio Grande do Sul (RS), safra 1997/1998. Após a colheita, os grãos foram separados em amostras para serem submetidos aos testes de secagem e armazenamento, realizados no Laboratório de Pós-Colheita, Industrialização e Qualidade de Grãos, do Departamento de Ciência e Tecnologia Agroindustrial, da Faculdade de Agronomia "Eliseu Maciel”, na Universidade Federal de Pelotas.

O experimento foi conduzido com os tratamentos em esquema fatorial $6 \times 4$, pela utilização de seis sistemas de umidades de colheita e métodos de secagem (18-I; 18-ECA; 18-ESA; 16-I; 16-ECA e 14$\mathrm{SP})$, combinados com quatro períodos de armazenamento (zero, quatro, oito e 12 meses), totalizando 24 tratamentos. O trabalho foi realizado em delineamento experimental inteiramente casualizado, utilizando três repetições.

A colheita foi realizada nas umidades de 18\% (colheita antecipada), 16\% (colheita usual) e 14\% (secagem na planta). A pré-limpeza foi realizada no referido laboratório, em máquina piloto de ar e peneiras até valores inferiores a 1\% de impurezas e/ou matérias estranhas. Para os grãos colhidos com umidade de $16 \mathrm{e}$ $18 \%$, os métodos de secagem empregados foram: intermitente, com temperatura do ar a $70^{\circ} \mathrm{C}(\mathrm{I})$; estacionário, com temperatura do ar a $45^{\circ} \mathrm{C}$ (ECA); e estacionário sem aquecimento do ar (ESA), exceto para os grãos com $16 \%$ de umidade. Em todos os métodos, os grãos de trigo atingiram em torno de $13 \%$ de água ao término da secagem. No trigo colhido com teor de água de $14 \%$ (SP), não foi realizada secagem complementar. As amostras secas foram acondicionadas em embalagens de algodão, com 4 kg, dispostas em pilhas, simulando sistema de armazenagem convencional, em condições atmosféricas não modificadas pelo período de 12 meses, com avaliações a cada quadrimestre.

$\mathrm{O}$ peso hectolitro $(\mathrm{PH})$ dos grãos foi determinado pelo emprego de balança modelo Dalle Molle. A pesagem foi realizada de acordo com a metodologia descrita nas Regras de Análise de Sementes (BRASIL, 1992). Os resultados das análises foram expressos em $\mathrm{kg}$ $h L^{-1}$. A umidade foi determinada através do emprego do método da estufa a $105 \pm 3^{\circ} \mathrm{C}$, por 24 horas, de acordo com BRASIL (1992), sendo os resultados expressos em porcentagem de teor água, em base úmida.

A proteína bruta foi determinada por espectrofotometria de infravermelho próximo (NIRS), sistema Bran+Lueble InfraAlyzer 360, com determinação prévia de curva de calibração, e os resultados foram expressos em porcentagem (base seca). Os teores de lipídios e de cinzas foram determinados de acordo com o procedimento descrito pela AACC (1995), métodos número 30-20 e 08-01, respectivamente. Os resultados das análises realizadas foram expressos em porcentagem. A acidez graxa foi determinada de acordo com o procedimento descrito pela AACC (1995), método número 58-15, após a extração dos lipídios em aparelho 
Soxleth e posterior titulação com $\mathrm{NaOH} 0,1 \mathrm{~N}$. Os resultados das análises realizadas foram expressos em porcentagem.

A moagem de trigo foi realizada de acordo com a AACC (1995), método número 26-95, utilizando moinho Brabender, modelo Quadrumat Sênior. As características viscoelásticas da massa foram determinadas em alveógrafo Chopin, modelo MA 95 (Villeneuve-la-Garenne Cedex, França) utilizando o método no $54-30$ da AACC (1995). Os parâmetros obtidos nos alveogramas foram tenacidade $(\mathrm{P})$, extensibilidade (L) e força geral do glúten (W).

Os resultados foram avaliados pela análise de variância e regressão linear em nível de 5\% de significância. As análises e os gráficos das equações de regressão foram elaborados com o auxílio do programa Microsoft Excel $2000^{\circledR}$, no modo estatístico.

\section{RESULTADOS E DISCUSSÃO}

Para teor de água dos grãos de trigo, foi verificado que a interação entre os sistemas umidades de colheita e métodos de secagem e período de armazenamento foi significativa $(\mathrm{P}>0,05)$. Nos grãos de trigo colhidos com $18 \%$ de umidade e secos em secador intermitente e secador estacionário com aquecimento, assim como nos grãos colhidos com $14 \%$ de umidade e secos na planta, as equações de regressão foram significativas (Figura 1), sendo verificado um aumento do teor de água dos grãos. Os maiores aumentos de umidade ocorreram no primeiro e no segundo quadrimestre e, após esse período, os grãos de trigo demonstraram tendência em atingir a umidade de equilíbrio higroscópico.

Em todos os tratamentos, o peso hectolitro (PH) reduziu com o aumento do período de armazenamento (Figura 2). Para os tratamentos 18-ECA e 14-SP, as equações de regressão linear não foram significativas $(\mathrm{P}>0,05)$. Os maiores valores de $\mathrm{PH}$ foram verificados nos grãos colhidos com $18 \%$ de umidade, sendo o menor valor para o grão colhido com umidade de $14 \%$ (secagem na planta). A redução do $\mathrm{PH}$, em decorrência do atraso na colheita, pode ser atribuída a processos metabólicos dos grãos e de organismos a eles associados, que provocam consumo de suas reservas nutritivas durante o armazenamento (FLEURAT-LESSARD, 2002).

O teor de proteínas, independentemente da condição de secagem, somente foi influenciado pelo período de armazenamento, sendo significativamente superior nas avaliações de oito e 12 meses. Os valores de proteína bruta da farinha de trigo nos meses zero, quatro, oito e 12 de armazenamento, em sistema convencional, foram 10,64, 10,73, 11,26 e 11,35, respectivamente. BHATTACHARYA \& RAHA (2002) verificaram que o conteúdo de proteína bruta apresentou tendência de aumento em grãos de milho armazenado por 12 meses. Esse aumento foi devido à formação de proteína fúngica, a qual não foi separada, sendo quantificada juntamente com a proteína bruta do grão. A perda no teor de proteínas durante a fase adiantada de incubação indica proteólise e formação de compostos mais simples, como aminoácidos, que são utilizados como fonte de nutrientes pelos fungos. Posteriormente, o conteúdo de proteínas tende a aumentar devido à formação de proteínas fúngicas, que são determinadas juntamente com as proteínas do grão, o que pode explicar os valores encontrados no presente trabalho.

Para o teor de cinzas da farinha de trigo, foi verificado que a interação entre os sistemas umidades de colheita e métodos de secagem e período de

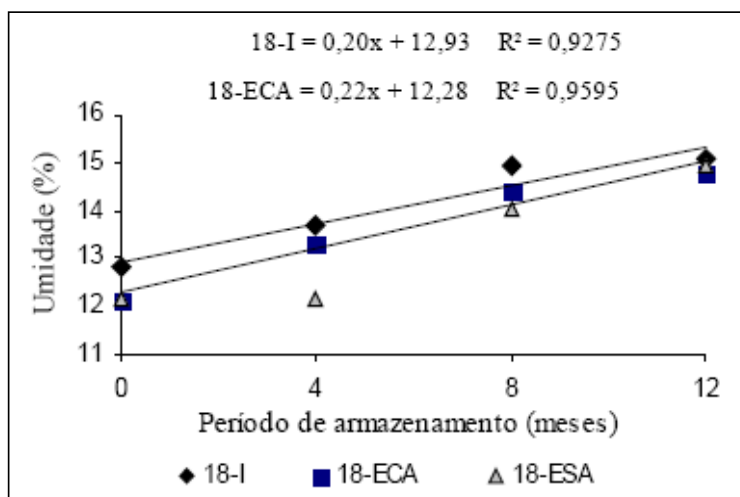

(a)

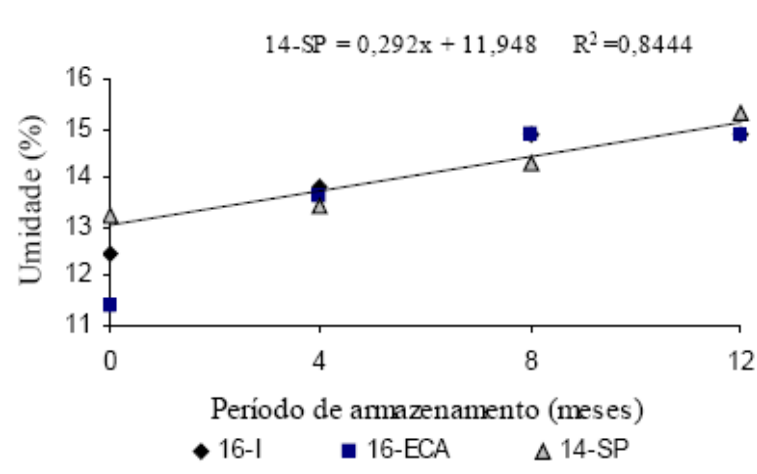

(b)

Figura 1 - Umidade de trigo da cultivar 'Embrapa 16', nas umidades de colheita e métodos de secagem 18-I; 18-ECA; 18-ESA (a) e 16-I; 16-ECA; 14-SP (b), todos armazenados em sistema convencional pelo período de 12 meses. Os grãos foram colhidos a 18,16 e $14 \%$ de umidade e secos em secador intermitente com ar a $70^{\circ} \mathrm{C}$ (I), secador estacionário com ar a $45^{\circ} \mathrm{C}$ (ECA), secador estacionário com ar sem aquecimento (ESA) e na planta (SP).

Ciência Rural, v.39, n.1, jan-fev, 2009. 


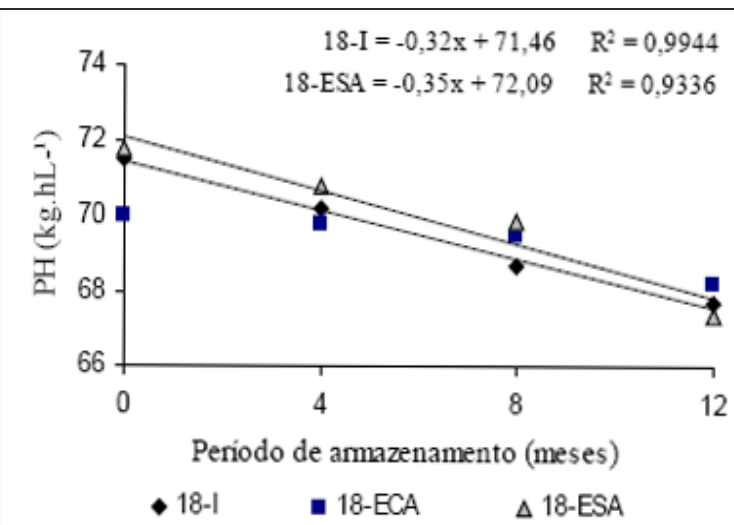

(a)

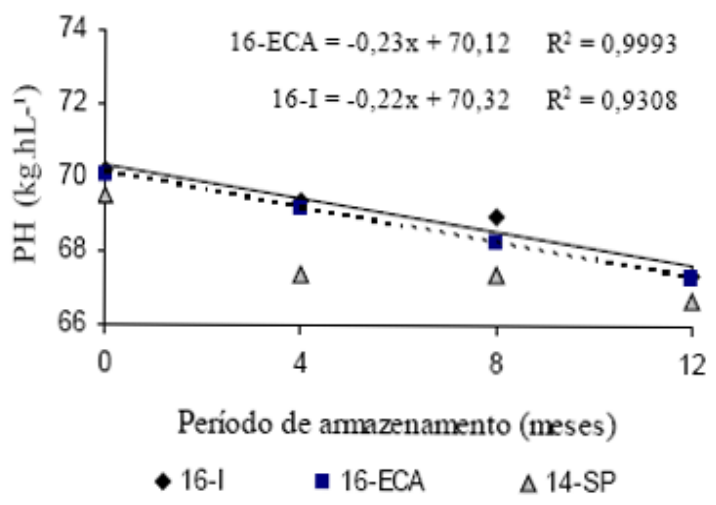

(b)

Figura 2 - Peso hectolitro (PH) de trigo da cultivar 'Embrapa 16', nas umidades de colheita e nos métodos de secagem 18-I; 18ECA; 18-ESA (a) e 16-I; 16-ECA; 14-SP (b), todos armazenados em sistema convencional pelo período de 12 meses. Os grãos foram colhidos a 18, 16 e $14 \%$ de umidade e secos em secador intermitente com ar a $70^{\circ} \mathrm{C}$ (I), secador estacionário com ar a $45^{\circ} \mathrm{C}$ (ECA), secador estacionário com ar sem aquecimento (ESA) e na planta (SP).

armazenamento foi significativa $(\mathrm{P} \leq 0,05)$. Nos grãos de trigo colhidos com $14 \%$ de umidade e secos na planta, a equação de regressão foi significativa, com coeficiente de determinação de 0,98 (Figura 3). Dentre os constituintes do trigo, o conteúdo de cinzas é a fração que apresenta menores variações em conteúdo total durante o armazenamento, e a variação ocorre devido à degradação da fração orgânica. A atividade metabólica dos grãos e microrganismos associados consome matéria orgânica, produzindo gás carbônico, água, calor e outros produtos, podendo alterar a proporção de minerais presentes no grão. Dessa forma, a determinação do teor de cinzas assume valores, proporcionalmente, maiores na medida em que a matéria orgânica é consumida (POSNER \& HIBBS, 1999). Em relação aos sistemas umidades de colheita e métodos de secagem estudados, foi verificado que, em grãos secos na planta, ocorreram os maiores acréscimos de cinzas com o aumento do período de armazenamento.

Em todos os sistemas umidades de colheita e métodos de secagem, ocorreu redução no teor de lipídios da farinha com o aumento do período de armazenamento (Figura 4), sendo significativas as equações de regressão 18-I, 16-ECA e 14-SP. Com a redução da umidade de colheita, ocorreu diminuição do teor de lipídios, sendo verificados menores valores em trigo seco na própria planta. Os lipídios presentes nos grãos estão na forma de triglicerídios, e a sua hidrólise, em ácidos graxos livres e glicerol durante o armazenamento, é resultante da respiração do próprio

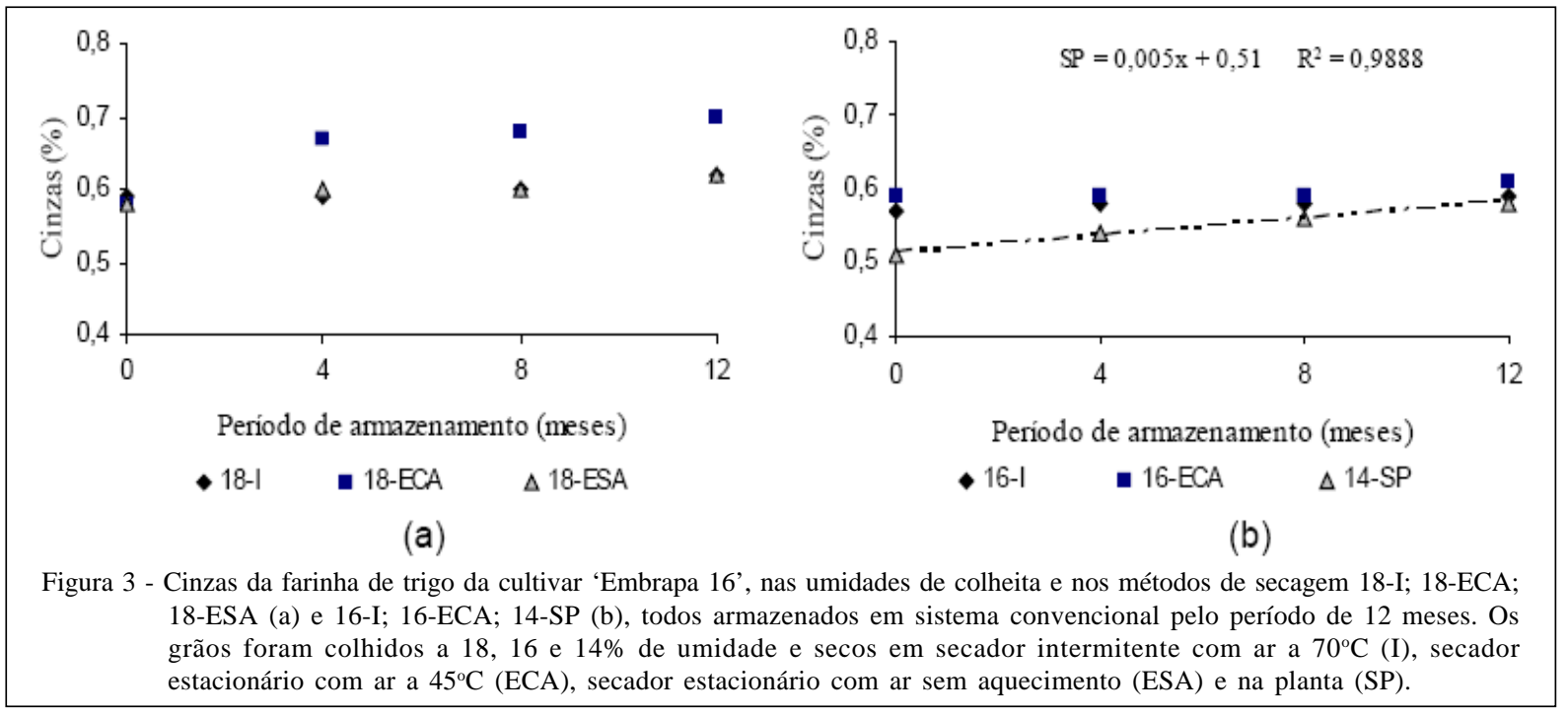

Ciência Rural, v.39, n.1, jan-fev, 2009. 


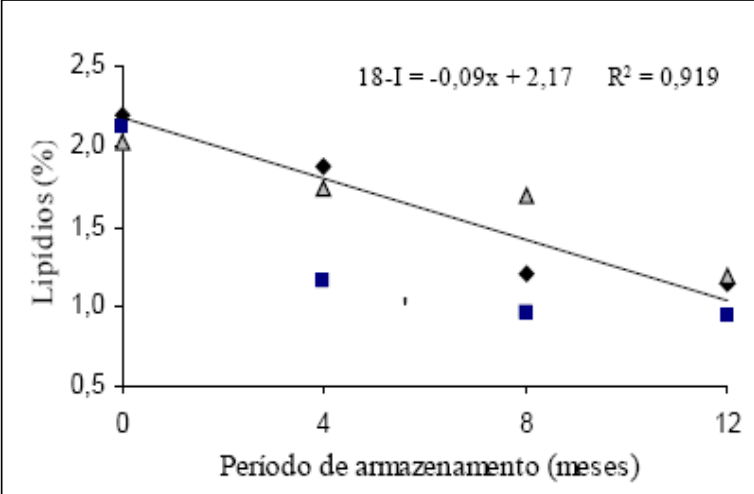

- 18-I 18-ECA $\triangle 18-E S A$

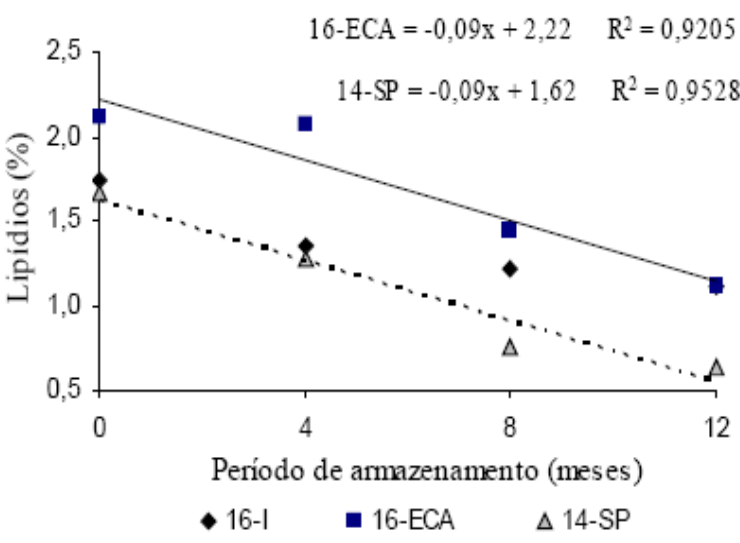

(b)

Figura 4 - Lipídios da farinha de trigo da cultivar 'Embrapa 16' nas umidades de colheita e nos métodos de secagem 18-I; 18-ECA; 18-ESA (a) e 16-I; 16-ECA; 14-SP (b), todos armazenados em sistema convencional pelo período de 12 meses. Os grãos foram colhidos a 18, 16 e $14 \%$ de umidade e secos em secador intermitente com ar a $70^{\circ} \mathrm{C}$ (I), secador estacionário com ar a $45^{\circ} \mathrm{C}$ (ECA), secador estacionário com ar sem aquecimento (ESA) e na planta (SP).

grão, dos processos de oxidação, da ação de enzimas, dentre outros fatores. A fração lipídica é a mais suscetível à deterioração e o grau de degradação é proporcional ao teor presente nos grãos (BHATTACHARYA \& RAHA, 2002; FLEURATLESSARD, 2002). Os resultados do presente trabalho estão de acordo com os obtidos por RUPOLLO et al. (2004) e MARINI et al. (2005), os quais também verificaram redução no teor de lipídios com o aumento do período de armazenamento de grãos de aveia.

A acidez graxa é um bom indicador de deterioração de grãos e seus produtos, pois a hidrólise dos lipídios ocorre mais rapidamente do que a de proteínas e carboidratos. Com isso, há condições de serem detectadas perdas logo no início, possibilitando a tomada de medidas adequadas para evitar danos maiores na qualidade do produto armazenado (MARINI et al., 2005). Para teor de acidez graxa da farinha de trigo, foi verificado que a interação entre os sistemas umidades de colheita e métodos de secagem e período de armazenamento foi significativa $(\mathrm{P} \leq 0,05)$. Nos grãos de trigo colhidos com $16 \%$ de umidade e secos em secador intermitente e secador estacionário com aquecimento, as equações de regressão foram significativas (Figura 5), sendo verificada elevação com o aumento do período de armazenamento. Os maiores valores de acidez graxa foram verificados em grãos de

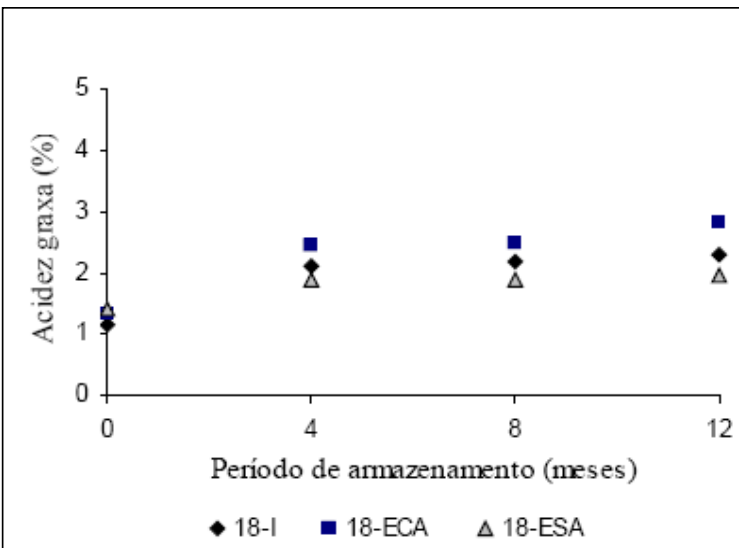

(a)

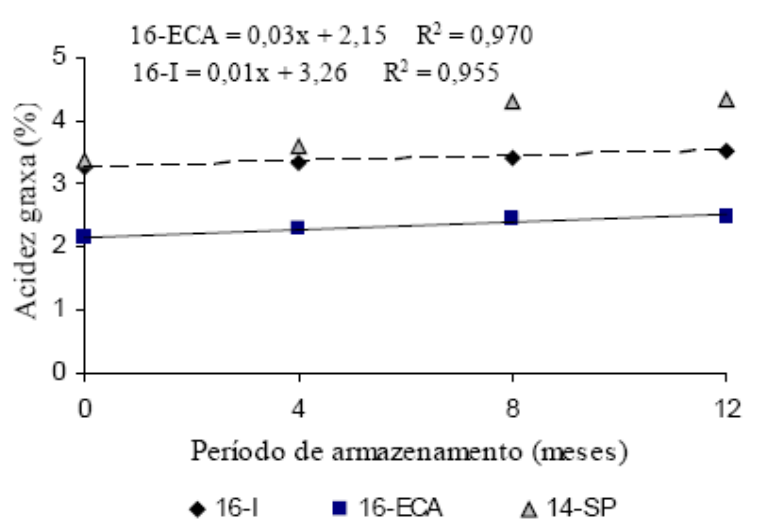

(b)

Figura 5 - Acidez graxa da farinha de trigo da cultivar 'Embrapa 16', nas umidades de colheita e nos métodos de secagem 18-I; 18-ECA; 18-ESA (a) e 16-I; 16-ECA; 14-SP (b), todos armazenados em sistema convencional pelo período de 12 meses. Os grãos foram colhidos a 18, 16 e $14 \%$ de umidade e secos em secador intermitente com ar a $70^{\circ} \mathrm{C}$ (I), secador estacionário com ar a $45^{\circ} \mathrm{C}$ (ECA), secador estacionário com ar sem aquecimento (ESA) e na planta (SP).

Ciência Rural, v.39, n.1, jan-fev, 2009. 
trigo secos na própria planta, o que indica que estes sofreram maior degradação.

A redução no teor de lipídios e o aumento no teor de ácidos graxos livres estão diretamente correlacionados com a velocidade e intensidade do processo deteriorativo dos grãos. A avaliação desses índices constitui-se em eficiente parâmetro para o controle da conservabilidade de grãos durante o armazenamento (MARINI et al., 2005). Os resultados do presente trabalho estão de acordo com os resultados relatados por BHATTACHARYA \& RAHA (2002), os quais verificaram redução no teor de lipídios com simultâneo aumento de acidez graxa durante o período de armazenamento de grãos.

A interação entre os sistemas umidades de colheita e métodos de secagem e períodos de armazenamento estudados não foi significativa para força geral do glúten (Wx10-4 J). O W foi de 93,20 x $10^{-4}$ Joules, em média, o que permitiu classificar o trigo como brando. O balanço preciso das propriedades viscoelásticas da massa é fator essencial para a determinação de uso final. A presença de glúten elástico é necessária tanto em farinhas destinadas à panificação, quanto para massas alimentícias, enquanto que um glúten menos elástico é requerido em farinhas destinadas à fabricação de bolos e biscoitos (DOBRASZCZYK\& MORGENSTERN, 2003).

\section{CONCLUSÕES}

Os grãos de trigo colhidos secos na planta apresentaram qualidade tecnológica inferior e menor conservabilidade ao armazenamento, em comparação com os grãos colhidos com umidades de 16 e 18\%, secos em secador intermitente com ar a $70^{\circ} \mathrm{C}$, estacionário com ar a $45^{\circ} \mathrm{C}$ e estacionário sem aquecimento, durante o período de 12 meses.

\section{AGRADECIMENTOS}

À Coordenação de Aperfeiçoamento de Pessoal de Nível Superior (CAPES) e ao Conselho Nacional de Desenvolvimento Científico e Tecnológico (CNPq), pelas bolsas; ao laboratório de Qualidade Industrial de Trigo da Embrapa Trigo, Passo Fundo, RS, pelas análises reológicas; à Secretaria de Ciência e Tecnologia do Rio Grande do Sul, pelo apoio por meio do Pólo de Inovação Tecnológica em Alimentos da Região Sul.

\section{REFERÊNCIAS}

AMERICAN ASSOCIATION OF CEREAL CHEMISTS. Approved methods of the American Association of Cereal Chemists. 9.ed. Saint Paul, 1995. V.2.

BHATTACHARYA, K.; RAHA, S. Deteriorative changes of maize, groundnut and soybean seeds by fungi in storage. Mycopathologia, v.155, n.3, p.135-141, 2002.

BIAGI, J.D. et al. Secagem de grãos para unidades centrais de armazenamento. In: LORINI, I. et al. Campinas: Instituto Bio Geneziz (IBG), 2002. V.1, p.289-308.

BRASIL. Ministério da Agricultura, do Abastecimento e da Reforma Agrária. Secretaria de Defesa Agropecuária. Regras para análise de sementes. Brasília: MAPA, 1992. 365p.

CARNEIRO, L.M.T.A. et al. Diferentes épocas de colheita, secagem e armazenamento na qualidade de grãos de trigo comum e duro. Bragantia, v.64, n.1, p.127-137, 2005.

DOBRASZCZYK, B.J., MORGENSTERN, M.P. Rheology and the breadmaking process. Journal of Cereal Science, v.38, n.2, p.229-245, 2003.

EDWARDS, S.G. Influence of agricultural practices on fusarium infection of cereals and subsequent contamination of grain by trichothecene mycotoxins. Toxixology Letters, v.153, n.1, p.29-35, 2004.

ELIAS, M.C. et al. Operações de pré-armazenamento, armazenamento e conservação de grãos. In: ELIAS, M.C. (Ed.) Pós-colheita de arroz: secagem, armazenamento e qualidade. Pelotas: Edgraf UFPel, 2007. p.147-244.

FLEURAT-LESSARD, F. Qualitative reasoning and integrated management of the quality of stored grain: a promising new approach. Journal of Stored Products Research, v.38, p.191-218, 2002.

KOCH, H-J. et al. Evaluation of environmental and management effects on Fusarium head blight infection and deoxynivalenol concentration in the grain of winter wheat. European Journal of Agronomy, v.24, n.2, p.357-366, 2006.

MARINI, L.J. et al. Efeito da secagem intermitente na estabilidade de grãos de aveia. Brazilian Journal of Food Technology, v.8, n.3, p.260-267, 2005.

POSNER, E.S.; HIBBS, A.N. Wheat flour milling. 2.ed. Minnesota: American Association of Cereal Chemists, 1999. 341p.

RUPOLLO, G. et al . Sistemas de armazenamento hermético e convencional na conservabilidade de grãos de aveia. Ciência Rural, v.34, n.6, p.1715-1722, 2004. 